\title{
1974 e o rock progressivo paulistano ${ }^{1}$
}

\author{
Matheus Lacorte Naman Angelo de Castro*
}

DOI: 10.11606/issn.2318-8855.v9i1p190-215

Resumo: No cenário cultural paulistano da década de 1970 - período de intensa atividade e transformações das expressões juvenis, da indústria cultural e da própria cidade - o ano de 1974 se apresenta como particularmente interessante dentro do campo do rock. É nesse momento que três influentes bandas do chamado rock progressivo se destacaram regionalmente, além de produzirem e/ou divulgarem discos marcantes: Snegs, de O Som Nosso de Cada Dia, Tudo foi feito pelo sol, dos Mutantes, e Criaturas da noite, de O Terço. Este artigo pretende, justamente, aproximar-se do referido universo musical tendo como eixo central o estudo das três bandas, objetivando compreender como se estabeleceu o circuito do rock progressivo em São Paulo na década de 1970 e o seu lugar no contexto de efervescência contracultural vivenciado pela capital paulista do período.

Palavras-chave: Mutantes; O Terço; Rock Progressivo; São Paulo; Som Nosso de Cada Dia.

* Professor de História, bacharel e licenciado pela Universidade de São Paulo (USP). E-mail para contato: matheus.lacorte.castro@usp.br.

${ }^{1}$ O presente artigo é fruto dos resultados de pesquisa obtidos através de Iniciação Científica, financiada pelo programa PIBIC/CNPq. Agradeço à entidade e ao Prof. Dr. José Geraldo Vinci de Morais, que tornou este empreendimento possível. 


\section{artigos}

1974 e o rock progressivo paulistano

No dia 22 de dezembro de 1974, a cidade de São Paulo assistiu ao encerramento do "Rock concerteza No1", um festival cujo objetivo era celebrar o fértil e empolgante ano do gênero no país (GOUVÊA, 1974a). Após uma semana de apresentações no Teatro Treze de $\mathrm{Maio}^{2}$, compreendendo promessas, revelações e músicos já consolidados, o fechamento do evento culminou na entrega do troféu "Rock 74". Como forma de homenagear aqueles que ativamente e melhor contribuíram para esse campo musical no período, foram premiados os artistas Ney Matogrosso (ex-Secos \& Molhados), Lucinha Turnbull (Tutti-Frutti), Gerson Tatini (Moto-Perpétuo), Norival Ricardo (ex-Secos \& Molhados), Cornélius (Made in Brazil), Tony Campelo, Jorge Mautner, Raul Seixas, O Terço (com o melhor show, no Masp, em outubro do mesmo ano), Serginho Dias (Mutantes) e Manito (Som Nosso de Cada Dia). Também houve a concessão de "prêmios especiais" aos jornalistas Ezequiel Neves Vornal da Tarde e revista Rock), Tárik de Souza (Jornal do Brasil e revista Rock), Carlito Maia (incentivo Rede Globo de Televisão) e Carlos Alberto Gouvêa (Folha de S. Paulo).

Ao reunir esse variado grupo de artistas, o evento se apresentou como paradigmático do espírito marginal e underground que campeava, sob variadas formas, no rock brasileiro do período: a contracultura. Proveniente do enfrentamento radical da juventude frente ao status quo e do questionamento anárquico da cultura ocidental e de massa (PEREIRA, 1986), a contracultura encontra suas primeiras manifestações

\footnotetext{
${ }^{2}$ Hoje extinto, à época localizado na rua Treze de Maio, no bairro da Bela Vista, região central da cidade.
} 


\section{Matheus Lacorte Naman Angelo de Castro}

nos EUA, com a geração beat ${ }^{3}$ e o movimento hippie ${ }^{4}$. Tendo lá o seu auge entre o fim da década de 1960 e o início dos anos de 1970 - periodização presente em grande parte da literatura - as práticas e cosmovisões desses grupos, no entanto, encontraram seu desenvolvimento no Brasil mais tardiamente, justamente no período aqui em questão (RIBAS, 2016). Na primeira metade da década de 1970, o país se deparou com um cenário cultural fortemente marcado pelas expressões visuais, verbais e musicais originárias da juventude anti-establishment inglesa e estadunidense. É sob a tutela repressiva do regime autoritário que a contracultura brasileira floresceu, mostrandose influente tanto como estética (GATTO, 2012) quanto como atitude política e comportamental, inclusive constituindo opção à passividade e ao engajamento "tradicional" da esquerda. ${ }^{51}$

Passando por uma complexa e variada gama de experiências musicais, desde o pioneirismo tropicalista até o progressivo paulista - para citar apenas duas balizas desse amplo leque - a contracultura foi uma espécie de fio condutor do rock brasileiro. Ney Matogrosso, por exemplo, membro do meteórico, midiático e efêmero Secos \& Molhados - grupo de sonoridade rebuscada, flertando com o folk, o glam rock e a psicodelia - diz sobre o período: "Não queria participar da sociedade e,

\footnotetext{
${ }^{3}$ Os Beatnicks foram jovens intelectuais que, ao final da década de 1950, manifestaram um espírito contestatório frente ao otimismo do pós-guerra e ao american way of life. Tiveram entre seus expoentes poetas e escritores como Allen Ginsberg, Jack Kerouak, Willian S. Burroughs, Lawrence Ferlinghetti, entre outros. Segundo Antônio Carlos Brandão, a designação beat surge a partir da publicação de Pé na estrada, de Kerouak, sugerindo a ideia de beatitude e purificação de espírito, com evidente influência das filosofias e religiões orientais (1990 apud SAGGIOTATO, 2008, p.31).

${ }^{4}$ Ao analisar a agitação contracultural de São Francisco na década de 1960, Paul Friedlander escreve: "Em seus cafés culturais da Columbus Avenue, foram os beats que classificaram seus parceiros de contracultura dos anos 60 como apenas um pequeno 'hip', daí o termo 'hippie'." (2002, p.270). O termo hip era associado ao não conformismo e a ideia de hipster, em oposição aos squares, os "caretas", "quadrados" e enquadrados no Sistema (PEREIRA, 1986).

${ }^{5}$ Segundo Patrícia Marcondes de Barros, no contexto após o Al-5: "havia três reações para o jovem da época: a luta armada, 'o desbunde da contracultura', ou, então, a conformidade com o sistema, tornandose, no linguajar contracultural, um 'careta'." (2004, p. 34 apud SAGGIOTATO, 2008, p.36).
} 


\section{artigos}

1974 e o rock progressivo paulistano

consequentemente, me coloquei à margem. Marginal por opção mesmo, e não por contingência da vida. Resolvi viver o que era de verdade pra mim, e isso me deixou extremamente feliz." (QUEIROZ, 2004, p. 46) ${ }^{6}$. Também analisando a disposição contracultural do início da década, Oswaldo Vechione - um dos líderes do Made in Brazil, grupo de orientação voltada para o "rock clássico", o blues e o hard rock, ${ }^{7}$ também premiado com o troféu “Rock 74" - diz em entrevista ao psicólogo e pesquisador Rafael Ribas:

Se o Rock brasileiro nos anos 1960 estava muito associado à Jovem Guarda, as bandas que estavam surgindo na Pompeia tinham outro referencial. Oswaldo Vecchione em entrevista nos contou que apesar de considerar a Jovem Guarda um movimento importante para o Rock brasileiro, ele a vê como um "Pop Rock". Enquanto na Jovem Guarda tinham mais influências de Neil Sedaka, Paul Anka, os músicos do Made in Brazil tinham a influência do Rock inglês, e de Norte Americanos como Chuck Berry e Jerry Lee Lewis. O referencial inglês das bandas da Pompeia fez com que o Rock brasileiro que até então era ligado à Jovem Guarda tomasse outros rumos, muito mais ao encontro do movimento contracultural que explodia no mundo no final dos anos 1960. (RIBAS, 2015, p. 209 apud RIBAS, 2016, p.50)

O que chama a atenção na lista de artistas premiados pelo festival de 1974, no entanto, é a presença evidente do rock progressivo, manifestação específica da contracultura musical: Mutantes, O Terço e Som Nosso de Cada Dia figuram entre os homenageados - sem mencionar a banda Moto-Perpétuo. As indicações, por sua vez, refletem o ano de destaque para esses grupos no cenário regional paulistano, marcado pela produção e divulgação de discos marcantes: Tudo foi feito pelo sol, Criaturas da noite e Snegs, respectivamente. No discurso de parte da imprensa, esses atores aparecem

\footnotetext{
${ }^{6}$ A identificação de Ney Matogrosso demonstra, justamente, a força da contracultura enquanto ideal, especialmente diante da realidade brasileira. Assim, era possível colocar-se, ao mesmo tempo, à margem comportamental e politicamente, como forma ativa e consciente de protesto, mas não comercialmente. Afinal, o sucesso dos Secos \& Molhados nessa esfera foi impactante e até mesmo atípico para o rock da década.

${ }^{7}$ A ideia de "Rock clássico" se refere aqui a uma aproximação à esfera do rock and roll em sua formação clássica, que, segundo Paul Friedlander teve como artistas representativos Fats Domino, Bill Haley, Chuck Berry e Little Richard (2002).
} 


\section{artigos}

\section{Matheus Lacorte Naman Angelo de Castro}

até mesmo como agentes ativos da transformação, profissionalização e consolidação do rock nacional vivenciada - aos menos aparentemente - ao longo de 1974.

Os três conjuntos, sua atuação e produções, certamente se apresentam como um importante eixo de investigação da rede de sociabilidade construída em torno do rock progressivo paulistano, cujo impacto no cenário musical regional e nacional é notável. Partindo da produção fonográfica das bandas e fundamentado, sobretudo, na crítica da imprensa cultural e periódica, o presente artigo busca mapear tal cenário ainda pouco conhecido e não devidamente explorado pela historiografia da música ${ }^{8}$ localizando e identificando espaços, artistas envolvidos, práticas, experiências de escuta e recepção. Tal investigação, em última instância, abre caminho para expandir o debate em torno do rock brasileiro na década de 1970, jogar luz sobre o lugar do estilo progressivo dentro desse recorte e compreender a importância desse universo musical no contexto de efervescência contracultural vivenciado pela capital paulista do período.

\section{O rock progressivo}

Definir o rock progressivo significa lidar com a complexa questão da classificação de gêneros e subgêneros musicais - que, no caso, torna-se tarefa ainda mais melindrosa, tendo em vista o marcante ecletismo e a natureza fronteiriça dessa forma musical. Nesse sentido, cabe aqui trabalhar com a concepção de que, mesmo diante da arbitrariedade e da artificialidade que as subdivisões estilísticas impostas pela indústria cultural e pela imprensa musical carregam, ao falar em rock, assim como em

\footnotetext{
${ }^{8}$ Aqui vale a citação de dois trabalhos relevantes que abarcam, em alguma medida, o universo do rock progressivo e, acima de tudo, refletem o crescente interesse em compreender a relevância histórica do rock brasileiro na década de 1970: a seminal investigação de Alexandre Saggiorato sobre as relações entre rock e política para o período (2008), e o mais recente estudo comparado de Paulo Gustavo da Encarnação, que coloca lado a lado o rock português e o brasileiro do período (2018).
} 


\section{artigos}

\section{4 e o rock progressivo paulistano}

jazz, música erudita e suas subdivisões, estamos lidando com tradições, as quais podem, em maior ou menor grau, serem circunscritas. Sobre o jazz, e o mesmo pode ser pensado para qualquer gênero musical, Diego Fischerman escreve:

Quando se diz que algo é 'jazz' não está se dizendo que suas características linguísticas intrínsecas correspondem a um determinado padrão estilístico, mas que esta música é feita por músicos de jazz, em um contexto associado com o jazz e que, em definitivo, circula pelo mercado como jazz. (2004, p.44, tradução nossa ${ }^{9}$ )

Particularmente sobre o rock progressivo, há o debate acerca da natureza excludente desta categorização (FRITH; RIBAC, 2018; ANDERTON, 2010), associando o estilo ao que seria, especificamente, sua variante sinfônica (Yes, Emerson Lake \& Palmer e Genesis, por exemplo). Apesar de a discussão ser fundamental, é justamente em torno desse referencial sinfônico que os grupos brasileiros em questão irão se basear, como veremos mais adiante. Vale refletir sobre a invenção dessa tradição para, em seguida, compreender sua recepção no Brasil.

Edward Macan, em sua obra Rocking the classics, descreve um processo no qual o rock progressivo, entendido como fenômeno social e produto de uma cultura (pós) hippie, emergiu da efervescência contracultural inglesa - condensada, dentro do rock, na psicodelia - durante a segunda metade dos anos 1960 e início da década seguinte. Isso pois o período presenciou a fragmentação do hippismo e a implosão dessa cultura, que até então era caracterizada por certa unidade, em múltiplas subculturas: o heavy metal $^{10}$, o jazz-rock, o glam-rock e o próprio progressivo (1997). A psicodelia perde,

\footnotetext{
${ }^{9}$ No original: "Cuando se dice que algo 'es Jazz' no se está diciendo tanto que sus características lingüísticas intrínsecas se corresponden con un determinado patrón estilístico, sino que esa música está hecha por músicos de Jazz, en un contexto asociado con el Jazz y que, en definitivo, circula por el mercado como Jazz."

${ }^{10}$ Macan se refere, com frequência, ao heavy metal junto de hard rock, muitas vezes como sinônimos. A ideia é de um campo "dionisíaco", como veremos mais a adiante. Vale, no entanto, fazer a diferenciação entre os termos, desfazendo essa confusão frequente. No início dos anos 1970, “Os 'velhos roqueiros' (em sua maioria, pertencentes à classe média) permanecem fiéis ao seu estilo predileto de música (ou seja, ao incipiente Hard Rock da década de 60) e ao lema 'sexo, drogas e Rock and Roll' que, juntamente
} 
Matheus Lacorte Naman Angelo de Castro

portanto, sua hegemonia, sendo o campo do rock tomado por outros discursos dessa derivados (GATTO, 2012).

Tal pulverização se inscreveu, por sua vez, em recortes nacionais, regionais e de classe, postulados - com uma pesada carga determinista e de maneira problemática, faz-se necessário ressaltar - por Macan. Nesse sentido, determinados elementos visuais, verbais e musicais da psicodelia em seu contexto ${ }^{11}$ e uma certa faceta do estilo teriam sido combinados com as especificidades sociais e culturais do sul da Inglaterra, sendo ali explorados de forma sui generis e levados ao paroxismo pelos músicos envolvidos. Culmina-se, assim, na formulação do progressivo enquanto estilo único e singular. Nas palavras de Macan,

O rock progressivo nunca poderia ter emergido do meio proletário responsável pela formação de gêneros como o heavy metal ou, posteriormente, o punk rock; através da década de 1970, a audiência do rock progressivo consistiu essencialmente de uma extensão de classe média e pós-hippie da contracultura. Da mesma forma, é difícil imaginar o rock progressivo emergindo nos EUA ao invés da Inglaterra (apesar de grande popularidade lá adquirida), assim como, por exemplo, o southern rock de bandas como os Allman Brothers nunca poderiam ter se desenvolvido fora do sudeste estadunidense. (1997, p. 19, tradução nossa) ${ }^{12}$

com seus textos compositivos, melodias e harmonias sofisticadas, faz apologia à busca pelo prazer fácil e pelo dinheiro a qualquer custo. Entrementes o 'novo público' (em grande parte, advindo do baixo extrato social) é atraído pelo ritmo mais forte e envolvente das guitarras distorcidas e das letras que tratam os problemas cotidianos de pessoas comuns, tais quais o sexo, a falta de dinheiro, o desemprego e a solidão". Este último, um hard rock mais explosivo, inconformista e provocador, é o heavy metal (FIORI e CONTANI, 2011).

${ }^{11}$ São esses: O Impacto do British Blues revival, com suas performances ao vivo e possibilidades elétricas, de amplificação, virtuosismo, improvisação e extensa duração instrumental; o ecletismo, experimentação, a fusão de gêneros e estilos, relacionados à ideia de uma "Música para a cabeça" e às experiências alucinógenas; a associação dessas aos discursos de jornada espiritual e de crítica aos rumos da sociedade contemporânea; os avanços tecnológicos de aparelhagem e gravação; a relação simbiótica entre músicos e plateia nos espaços dos clubes underground; a liberdade estética atípica dada pela indústria fonográfica nesse momento; a formação de um circuito de rádios e imprensa undergound (MACAN, 1997).

12 No original: "Progressive rock could have never emerged from the working-class milieu that was responsible for the formation of genres such as heavy metal and later, punk rock; throughout the 1970s, progressive rock's audience consisted largely of a middle- class, post-hippie extension of the counterculture. Likewise, it is difficult to imagine the progressive rock style having developed in the United States rather than England (although it eventually did achieve great popularity there), just as, for 


\section{artigos}

\section{4 e o rock progressivo paulistano}

Como resultado desse processo, o rock progressivo se apresenta em 1972 como um estilo já consolidado, em torno do qual se associavam diversos grupos: Pink Floyd, Yes, Genesis, Emerson, Lake \& Palmer, King Crimson, Gentle Giant, Van der Graaf Generator, Jethro Tull, entre outros. Esses agentes estavam, portanto, inseridos em torno de uma tradição, compartilhando elementos comuns em suas agências artísticas: o flerte constante com elementos eruditos (seja na forma, na performance ou na recepção) na tentativa de expandir as fronteiras estilísticas do rock; a concepção de "música para a cabeça", a isso relacionada; intensa sobreposição de camadas acústicas e elétricas - com destaque para o uso de sintetizadores - de intensidade, de sonoridades, assim como de expressões e temáticas modernas e pré-modernas; uma tensão e contradição inerentes ao estilo; e seu marcante ecletismo. Esses seriam os mais elementares atributos do rock progressivo. ${ }^{13}$

instance, the southern rock of bands such as the Allman Brothers could have never developed outside of the southeastern United States"

${ }^{13}$ Podemos exemplificar tais características e delimitá-las mais claramente referenciando os artistas citados. Os grupos mencionados, todos britânicos e formados entre o final da década de 1960 e o início dos anos 1970, compartilham uma série de padrões e posturas artísticas. Dentre essas, podemos citar: composições longas, com enfoque instrumental e estruturadas em movimentos articulados (Echoes de Pink Floyd, e Supper's Ready de Genesis); intenso ecletismo (como no Jazz-fusion de King Crimson e Van der Graft Generator, ou no folk-rock de Jethro Tull) e conexão com a erudição (em peças como Knife-edge, de Emerson, Lake \& Palmer, que contém trechos da Suíte francesa №1, de Johann Sebastian Bach); utilização ampla de teclados (mesmo os grupos que não possuíam tecladistas ou pianistas fixos, faziam uso recorrente desses instrumentos - como é o caso de King Crimson e a utilização do mellotron alternando entre piano, elétrico e acústico, órgãos e sintetizadores); virtuosismo (verificável nas intricadas composições e performances de Gentle Giant e Van der Graft Generator; nas métricas e compassos atípicos, como em Firth of Fifth de Genesis ou Money de Pink Floyd; além dos complexos solos de Keith Emerson, Rick Wakeman e Steve Howe); utilização de temáticas críticas à realidade contemporânea, através de roupagens de ficção científica, medievalismo, distopias e utopias, compartilhando tanto elementos tradicionais quando futuristas (como a jornada espiritual retratada na música Close To The Edge de Yes; as visões mais niilistas do porvir em Epitaph, de King Crimson, e na peça Tarkus, de ELP; ou os temas medievais de The Court Of The Crimson King, de King Crimson, e da cultura europeia, como as referências a Pantagruel e Gargântua em The Adventure Of Panurge, de Gentle Giant); e álbuns conceituais (Dark Side Of The Moon, de Pink Floyd e The Lamb Lies Down On Broadway, de Genesis). 


\section{artigos}

\section{Matheus Lacorte Naman Angelo de Castro}

\section{O Progressivo Paulistano}

Do outro lado do atlântico, a década de 1970 assistiu à trajetória de muitos grupos brasileiros confluírem no sentido da tradição progressiva. O ano de 1974 se mostra como um marco desse processo, quando tal convergência evidencia o surgimento de uma rede musical, com artistas gravitando em torno de convenções estéticas do rock progressivo, além de espaços de reprodução e de sociabilidade na cidade de São Paulo.

Quanto a esses últimos, uma apreciação dos anúncios e críticas de shows na grande imprensa periódica revela a centralidade de um circuito de teatros e auditórios: Mackenzie, Rio Branco, Ibirapuera, MASP, Treze de Maio e Bandeirantes. Os dois últimos foram particularmente relevantes. Se, por um lado, o Teatro Bandeirantes foi o único desses que recebeu temporadas dos três conjuntos, o Teatro Treze de Maio foi o palco da já citada premiação que celebrou o ano, e “(...) que em 1974 revelou-se como um autêntico templo do rock, abrindo suas portas para vários conjuntos, dando seu incentivo ao movimento." (GOUVÊA, 1974d, p. 24) ${ }^{14}$.

Os mesmos anúncios e críticas de apresentações apontam para a existência de uma rede conectada de músicos: Jazzco, Casa Das Máquinas, Vímana, Burmah, Arnaldo Baptista, Apokalypsis, Terreno Baldio e Moto Perpétuo - citando somente aqueles mais próximos e comumente identificados com a vertente progressiva - aparecem, muitas vezes, dividindo o palco em festivais com Os Mutantes, O Som Nosso e O Terço. São comuns, nesses espaços, as jam sessions nas quais se intercambiavam os membros das bandas. Além dessa, outras práticas musicais se apresentam, como a reprodução dos LPs inteiros ao vivo e de repertório inédito (GOUVÊA, 1974b; GOUVÊA, 1974g, GOUVÊA,

\footnotetext{
${ }^{14}$ Aqui é pertinente um comentário sobre o quão sugestivo é o nome do festival: "Rock concerteza", em um jogo de palavras com a expressão "com certeza" e o termo "concerto". Junto da ideia de afirmação do rock, tem-se, assim, uma alusão ao espaço por excelência da música erudita, em consonância com as práticas e expressões ecléticas e de contemplação do progressivo.
} 


\section{artigos}

1974 e o rock progressivo paulistano

1974j).

Apesar de serem enquadrados e se enquadrarem dentro de um horizonte sonoro comparável a grupos como Yes, Genesis e Emerson Lake \& Palmer, os grupos em questão e a rede de músicos a esses relacionada não são classificados com o rótulo "rock progressivo"15. Consequentemente, apesar de identificarmos uma rede, essa não é claramente definida ou conceituada monoliticamente para e na prática de seus agentes, o que se evidencia na sobreposição de tradições musicais e de plateias, dentro e fora do campo do rock. As próprias jam sessions ${ }^{16}$ já citadas são, justamente, exemplo dessa interpenetração, sendo um modo de performance mais diretamente relacionado ao universo de comunhão e liberdade improvisacional do rock psicodélico - em oposição à busca do progressivo por estruturação e ordenação formais definidas, através da referência sinfônica e programática da música erudita ocidental e com reflexo em um performance "engessada", constantemente voltada para a reprodução fiel das gravações em estúdio ${ }^{17}$ (MACAN, 1997).

Outra esfera em que tal sobreposição é perceptível é a da recepção dos ouvintes. As impressões trazidas pelos articulistas contemporâneos trazem variadas experiências de escuta por parte do público presente nos shows desses grupos. Há descrições de padrões mais contemplativos que são peculiares ao rock progressivo, com sua natureza apolínea; mas também de níveis de escuta díspares e até mesmo

\footnotetext{
${ }^{15}$ Durante a investigação dos periódicos, o termo exato e suas variantes, como "música progressiva", revelaram-se inexistentes ao longo do ano de 1974 para a Folha de S. Paulo. Já no Jornal do Brasil, entre 1973 e 1974, é utilizado para categorizar elementos tão díspares quanto os grupos Grateful Dead, Mahavishnu Orchestra, The Who, David Bowie, Astor Piazzolla, e A Bolha.

${ }^{16}$ Vale ressaltar a origem do termo relacionado à emergência do bebop nos EUA da década de 1940 e, portanto, externo, em sua origem, ao campo do rock (CALADO, 1990).

${ }^{17}$ Há múltiplas exceções a essa concepção de performance dentro do rock progressivo, sendo o grupo King Crimson paradigmático, com sua notável tradição de improviso e experimentação nas performances ao vivo. Isso revela e reforça a complexidade em definir rigidamente o estilo.
} 


\section{Matheus Lacorte Naman Angelo de Castro}

antagônicos nesse sentido, como aqueles ligados à dança ou à expressão física mais violenta, o lado dionisíaco ${ }^{18}$. Por vezes tal incompatibilidade aparente é vista em uma mesma apresentação, como, por exemplo, nos mostra uma reportagem da Revista Veja sobre os Mutantes:

Um delírio. Os jovens que lotavam a enorme plateia do Teatro Bandeirantes, em São Paulo, subiam em poltronas estalantes para dançar e gritar. (...) Deitado num dos corredores, crucificado no carpete, um rapaz meneava ritmicamente a cabeça. Passando mal? - alguém indagou. Olhos fechados, a não-vítima respondeu: “Me deixa aqui. Isso é felicidade, cara". (...) Segundo Sérgio, o único sobrevivente do grupo original (...), o importante é o sucesso, comprovado pelas 30 poltronas que seus alucinados admirados quebraram (...). Um número [solo de piano eletrônico] religiosamente ouvido pela plateia, também respeitosa quando Sérgio se senta no chão do palco, acende uma dúzia de varetinhas de incenso e toca (...) a sitar (sic) que ganhou de presente do mago Ravi Shankar. (PENIDO, 1974, p.82)

Na crítica da Folha de S. Paulo a um festival ao ar livre realizado no parque Ibirapuera - com participações do Terço e de uma jam-session com Pedrinho e Pedrão do Som Nosso, além de Liminha e Dinho, ex-Mutantes - Carlos Alberto Gouvêa (1974k, p.24) relata:

Tudo aconteceu na mais perfeita calma, e nenhum acidente ou incidente ocorreu (...). Não houve policiamento, e também não seria necessário. Todos que compareceram ao parque pertenciam a uma só torcida - a do "rock and roll". Todos queriam rock, e Magnólio com os poucos recursos que dispunha, soube contentar as pessoas.

Outras performances, por sua vez, demonstram diferentes padrões de escuta.

De acordo com Victor Henrique de Resende e Ana Cláudia de Assis (2016, p.116):

(...) segundo uma reportagem no Jornal de Música e Som, de 1975, “nos shows do Terço, no teatro Bandeirantes, várias cadeiras foram quebradas e todos assistiam o espetáculo em pé, nos braços das poltronas", o que mostra as diversas recepções e performances do público com relação à música do grupo.

\footnotetext{
${ }^{18}$ O rock psicodélico carregava consigo uma tensão da contracultura, entre a busca do prazer em si mesmo ou essa no sentido de uma melhor compreensão e transformação da realidade, com a expansão da consciência e a superação das restrições do mundo material e conservador. Com a fragmentação da cultura jovem na década de 1970, dois dos maiores herdeiros da psicodelia assumem e exacerbam cada um uma das faces desse conflito. O heavy metal, com sua ênfase hedonista no prazer carnal e material, tratando de temas como sexo, drogas e festividade, constituem um paradigma dionisíaco do rock. Já o rock progressivo, valorizando as questões da jornada espiritual, da crítica à sociedade contemporânea e com sua fascinação por determinados tipos de narrativa, expressa a esfera apolínea (MACAN, 1997).
} 


\section{artigos}

1974 e o rock progressivo paulistano

Mais uma vez, nos deparamos com a simultaneidade de posturas apolíneas e dionisíacas no campo da recepção.

Tratando-se da música em si, a sobreposição de identidades sonoras é inerente ao rock progressivo, dando-se no caso dos grupos aqui abordados em diferentes níveis. Para além do horizonte sonoro do rock progressivo sinfônico, no modelo de Yes e Emerson Lake \& Palmer, há nos três conjuntos cruzamentos dentro do rock, como com a estética mais pesada do hard rock, por exemplo. Especificamente, nos Mutantes destaca-se uma contemplação lisérgica hippie e "pré-progressiva" (SANTOS, 2010); com o Som Nosso, escuta-se um flerte significativo com o jazz, somado, mesmo que de maneira tímida, às camadas regionais perceptíveis pelo uso da viola (PAIVA, 2017); e O Terço, por fim, traz o ideário do rock rural e até mesmo da "música mineira", em referência à sonoridade do movimento Clube da Esquina (RESENDE E ASSIS, 2016).

A despeito da falta de denominação clara da tradição na qual se inserem, sendo classificado de maneira geral como artistas de "rock", o progressivo internacional chega com impacto no Brasil. Para além de simples inspiração para os "rockeiros" daqui, o estilo se mostrou também como produto consumido por um público constituído mesmo que insípido, fechado em si mesmo e em uma rede restrita. Isso é perceptível nos interessantes resultados de uma pesquisa de opinião feita pela rádio do Jornal do Brasil e divulgada em seu periódico:

Pela primeira vez, ouve-se a opinião do apreciador de rock no Brasil. O programa Música Contemporânea, da Rádio JORNAL DO BRASIL, após seis chamadas em sua programação, e uma semana para o prazo do envio de respostas, recebeu 380 cartas, numa consulta sobre os conjuntos de rock preferidos dos ouvintes. Foram votados 98 grupos, no $1^{\circ}$ pool radiofônico de música contemporânea. Pela ordem: 10) Deep Purple; 9) Som Nosso de Cada Dia; 8) Tangerine Dream; 7) King Crimson; 6) Focus; 5) Led Zeppelin; 4) Genesis; 3) Emerson Lake and Palmer; 2) Yes; 1) Pink Floyd. (SOUZA, 1974a, p. B05)

Dos dez mais votados, temos, portanto, cinco grupos ingleses tradicionalmente inseridos no estilo progressivo e classificadas como exemplares do mesmo; dois 


\section{artigos}

\section{Matheus Lacorte Naman Angelo de Castro}

conjuntos europeus também ligados a essa tradição (Focus e Tangerine Dream), sobretudo em concepções expandidas (ANDERTON, 2010); outros dois um pouco mais distantes da referida esfera, mas ainda sim com conexões (Deep Purple e Led Zeppelin); e, de maneira bastante curiosa, um dos nossos agentes-objeto, logo no seu ano de estreia no mercado fonográfico.

É importante ressaltar que, ao contrário do que se imagina frequentemente, o rock progressivo obteve significativo sucesso comercial dentro e fora da Inglaterra, chegando a ser o estilo mais lucrativo do período (MACAN, 1997). Ainda no Jornal do Brasil, em uma das poucas recorrências à expressão entre 1973 e 1974, Tárik de Souza apresenta evidências do fértil ano para os "roqueiros" brasileiros. Diante de sua "constatação inegável", o entrevistado Antônio Carlos Duncan - responsável pela marca Harvest, da Odeon - trata do assunto:

Outra constatação inegável: 1974 foi o ano de implantação do rock no Brasil (...) “Esse foi o ano do progressismo, do rock progressivo no Brasil. Editamos todos os Pink Floyd já lançados pela Harvest International no Brasil e a média de vendas foi acima de 25 mil, sendo que o Dark Side Of The Moon (último LP) chegou aos 70 mil". Duncan pretende promover a rotação de rocks de vários países dentro do selo (...), além de aguardar a autorização da matriz para começar os trabalhos com o produto ativo, $\mathrm{O}$ Terço, O Veludo e O Vímana. (1974b, p.B2)

\section{Mutantes, O Terço e Som Nosso de Cada Dia}

Nesse contexto, apesar de traçarem percursos profissionais bastante diferentes, Mutantes, Terço e Som Nosso de Cada Dia compõem um panorama musical roqueiro, sintonizado com as ondas contraculturais e progressivas que se propagavam pelo mundo. Vale observar o caminho trilhado pelos mesmos para pensar sua inserção na história do estilo.

A banda Mutantes foi formada em 1966, na cidade de São Paulo, por Rita Lee Jones (voz e percussão), Arnaldo Dias Baptista (voz, baixo e teclados) e seu irmão Sérgio Dias Baptista (voz e guitarra). O grupo surgiu a partir do conjunto Six Sided Rockers - 


\section{artigos}

1974 e o rock progressivo paulistano

fusão dos Wooden Faces, de Arnaldo, e das Teenage Singers, de Rita. Com o ingresso de Sérgio e a saída de outros membros, configurou-se o trio que atuou de forma central no movimento tropicalista. A partir de 1969 o grupo passou a contar com o baixista Liminha (Arnolpho Lima Filho) e com o baterista Dinho Leme (Ronaldo P. Leme); formação essa que durou até a saída de Rita em 1972.

Durante a década de 1970, sobretudo com o esvaziamento do tropicalismo e a influência crescente do rock e da psicodelia, a banda ingressou na sua fase progressiva, gravando um LP fundamental para a história do estilo no país, inclusive com relativo impacto comercial (BAHIANA, 2005): Tudo foi feito pelo sol, de 1974, cuja formação mantinha apenas Sérgio dos Mutantes originais. Nesse, Antônio Pedro Medeiros (baixo), Rui Motta (bateria) e Túlio Mourão (piano, órgão e sintetizadores) completavam o quarteto. Nesse momento, o referencial do grupo esteve clara e diretamente ligado ao rock progressivo inglês, como podemos perceber no discurso dos músicos. Em entrevista à revista Rock: a história e a glória, eles relatam:

[Sérgio Dias] "Os Beatles me mostraram as harmonizações da música, suas cores. Emerson, Lake and Palmer, Yes e King Crimson me mostraram, mais tarde, o espaço e o tempo, a quarta dimensão da música (...). [Túlio Mourão] Meu contato com o rock foi através dos caras do Veludo, em 73, eles ainda eram veludo elétrico. Vinha de uma formação erudita, ainda que mesclada com música popular. A partir daí comecei a sonhar com mil teclados. A sonhar os mil recursos eletrônicos do Emerson, Lake and Palmer, a sonhar com sintetizadores (...). [Rui Motta] Pra mim, hoje, o melhor baterista do mundo é o Palmer, o cara que mais me diz coisas, que me motiva. Gosto muito do Alan White do Yes. (...) [sobre o rock] Eu não sei o que é. O caracteriza o rock são duas guitarras, um baixo e uma bateria. Acho rock and roll o Bill Haley, o Little Richard. Mas de 68 pra cá o rock é aberto pra todos os lados, é elástico, abrange desde Yes até Hermeto. (...) A nossa música, a música dos Mutantes, não segue uma linha. Ela tem o nosso 'feeling'. Ao mesmo tempo a gente toca a matemática de Pitágoras, toca clássico ou rock (...). [Antonio Pedro de Medeiros] Meus baixistas prediletos são Jack Bruce, Chris Squire, do Yes, Glen Hugles do Deep Purple e Hugh Hopper do Soft Machine." (ZANETTI, 1975, pp. 17-18)

O conjunto O Terço também surgiu na década de 1960, em 1968. Inicialmente da cidade do Rio de Janeiro, posteriormente os músicos se estabeleceram e 


\section{Matheus Lacorte Naman Angelo de Castro}

desenvolveram sua trajetória profissional em São Paulo, como um trio formado por Sérgio Hinds (baixo e guitarra), Jorge Amiden (guitarra) e Vinícius Cantuária (bateria). Esse período inicial, além da gravação de seu primeiro LP, O Terço, de 1970, foi marcado pela forte presença da banda em festivais. Com a saída de Amiden e a entrada de Cezar de Mercês (baixo), o grupo lançou seu segundo disco, Terço, de 1973, cuja sonoridade já evidenciava aproximação na direção do rock progressivo.

Essa influência se tornou evidente no LP Criaturas da noite $(1975)^{19}$, quando o grupo, já sem Cantuária, contava com a presença de Sérgio Magrão (ex-técnico de som da banda e baixista), Luiz Moreno (bateria), e um tecladista indicado por Milton Nascimento, Flávio Venturini. Cézar de Mercês havia se afastado, mas continuava como compositor. Para além do lado progressivo, o álbum apresenta múltiplas identidades sonoras, como influências da "música mineira", do hard rock e do rock rural - sendo a última devido à aproximação e colaboração de seus membros com Sá e Guarabyra (RESENDE e ASSIS, 2016). Segundo Venturini:

O Genesis foi uma banda que nos influenciou muito, porque é uma banda que tem muita harmonia e a música mineira tem isso, então eu acho que a gente se identificou muito com aquela influência clássica e erudita que eles tinham. Eu digeri isso na minha música e levei para o grupo O Terço. Quando eu comecei no grupo O Terço, eles vinham de um período bem folk, que tocava nos festivais de música brasileira, depois eles passaram para uma coisa mais hard rock, e quando eu entrei, levei uma linguagem progressiva que deu super certo na época. Eu acho que O Terço foi a grande banda de rock progressivo no Brasil de todos os tempos. (RESENDE e ASSIS, 2016, p. 121)

Por fim, O Som Nosso de Cada Dia foi formado em 1972, na cidade de São Paulo, por Manito (multi-instrumentista - piano, teclados, sintetizadores, saxofone, violino e flauta - e ex-integrante do conjunto Os Incríveis), Pedro Balzanza (o Pedrão, assumindo baixo, guitarra e vocal) e Pedrinho Batera (bateria e vocais). Em 1974, além do destaque

\footnotetext{
${ }^{19}$ Apesar de laçado em 1975, o disco já vinha sendo gravado ao longo do ano de 1974, inclusive com apresentação de seu repertório em shows (GOUVÊA, 1974b). É digno de nota, aliás, que a canção que mais notavelmente carrega elementos do rock progressivo neste LP é significativa e simbolicamente intitulada "1974", refletindo a efervescência que o ano vivenciou no país com relação ao estilo.
} 


\section{artigos}

1974 e o rock progressivo paulistano

obtido por se apresentarem como banda de abertura no show de Alice Cooper em São Paulo, o trio lançou seu primeiro e único LP com essa formação: Snegs, com evidente referencial sonoro progressivo, nos moldes de Emerson, Lake \& Palmer (PAIVA, 2017). Tal "importação" foi também percebida pela imprensa: “No cenário brasileiro do rock, o conjunto Som Nosso se Cada Dia lançou o 'Snegs' que, como primeiro disco, deixa a desejar pelo excesso de influência adotada de Emerson, Lake and Palmer e Yes; mas, para o futuro promete." (GOUVÊA, 1974c, p. 24).

\section{4: o ano do rock no Brasil?}

Mesmo os mais céticos articulistas da grande imprensa ${ }^{20}$, vislumbraram com certo otimismo a atuação dos três conjuntos que alcançavam expressão na época. Os Mutantes, que, a princípio e naquela conjuntura, insistiam em "agredir o rock nacional" (SOM..., 1974, p.22), meses depois passaram a ser retratados de forma bastante diferente. O mesmo veículo divulgou a seguinte crítica sobre a já citada temporada de shows no Teatro Bandeirantes:

Quem foi neste último fim de semana assistir os Mutantes, no Teatro Bandeirantes, teve uma agradável surpresa. (...) Finalmente, após quase oito anos de existência, os Mutantes passaram definitivamente a ser um grupo de rock, classificados entre os melhores existentes em nosso país, e pronto para a exportação. [Sobre o som pesado] (...) cheio de influências, desta vez benéficas, por parte de Emerson, Lake and Palmer, Yes e Uriah Heep. (...) Em resumo, os Mutantes nunca estiveram melhor do que nessa nova fase." (GOUVÊA, 1974f, p.34)

Em sua retrospectiva do ano, tratando da mesma apresentação, a Revista Veja reforçou essa visão positiva, opondo o grupo ao contexto desfavorável: “Com seu rock

\footnotetext{
${ }^{20}$ É nos termos da discussão feita por Ana Maria Bahiana em 1979 - ainda no calor do momento, digase de passagem - (2005) que Carlos Alberto Gouvêa faz nas páginas da Folha de S. Paulo um balanço do rock nacional até aquele momento, em julho de 1974. O saldo, desde os Avalons na década de 1950 até o Som Nosso de Cada Dia no momento do debate, é de um movimento absolutamente frágil. As causas dessa debilidade são apontadas como a demasiada influência estrangeira, suprimindo a possibilidade de um caminho próprio a ser trilhado pelos "rockeiros" nacionais; e a falta de "pés no chão", ou seja, a exacerbada prepotência, ausência de profissionalismo e seriedade (1974e, p.18).
} 


\section{Matheus Lacorte Naman Angelo de Castro}

nativo e selvagem, entremeado por músicas de imponente serenidade, o grupo mostrou-se imune à mediocridade que campeia no rock pátrio." (LANCELLOTTl; PENIDO; DUTRA; SOUZA, 1975, p.46) ${ }^{21}$.

As críticas direcionadas ao Som Nosso de Cada Dia começaram a aparecer com a divulgação do LP Snegs e repetiam essencialmente a mesma visão: apesar da excessiva influência alienígena, o grupo se mostrava absolutamente promissor e superior ao campo roqueiro tupiniquim ${ }^{22}$. Em dezembro, a descrição é de um conjunto "apontado pela crítica como um dos melhores do gênero" (GOUVÊA, 1974g, p.38).

O Terço, por fim, aparece como o mais bem avaliado pela crítica ao longo de todo o segundo semestre. Sobre uma apresentação no Teatro Bandeirantes: “(...) os responsáveis pela geração de energia foi (sic) um super-grupo, 'O Terço', que a cada apresentação vai se firmando como uma das melhores bandas de rock do Brasil, uma das únicas que consegue com seu repertório fazer a plateia se levantar e cantar com eles." (GOUVÊA, 1974h, p.36).

Dessa forma, aos poucos observamos como o discurso da imprensa transformou um otimismo passageiro em euforia. Com claro impacto e contribuição do Terço, Mutantes e Som Nosso, a ideia de que 1974 se apresentou como ano fundamental para o rock nacional surgiu com força. As retrospectivas e os inventários de melhores do ano são sintomáticos nesse sentido: A Revista Veja elegeu o show dos

\footnotetext{
${ }^{21}$ Vale chamar atenção para a diferença da Revista Veja entre o período em questão e os dias de hoje. Sendo mais aberta em comparação com seu viés atual, claramente conservador, tais temas contraculturais e da juventude eram tratados com maior liberdade, através de um grupo de jornalistas relevantes do período, como o já citado Tárik de Souza.

${ }^{22}$ Vemos exemplos em: "Mesmo guiadas por sensíveis influências dos grupos Yes e Led Zeppelin, das sete faixas deste LP emanam ondas de energia superiores à frequente debilidade do rock nacional. Parte dessa surpresa cabe aos voluntariosos teclados acionados por Manito (ex-Incríveis). Outro tanto à densidade de algumas letras, como a de Direccion de Aquarius, montada em cuidadoso anglo-espanhol (...)." (SOUZA, 1974c, p. 108,); e "Mais um sinal de vida do rock nacional que, ainda lentamente, caminha para a maturidade. Snegs é o melhor lançamento do gênero esse ano e o grupo deixa a impressão de um grande potencial de desenvolvimento na faixa Massavilha." (PEREIRA, 1974, p.B06)
} 


\section{artigos}

1974 e o rock progressivo paulistano

Mutantes no Teatro Bandeirantes como um dos dez melhores de 1974 (LANCELLOTTI; PENIDO; DUTRA; SOUZA, 1975); enquanto o "Troféu Rock 74", como citado anteriormente, o fez com relação ao Terço e sua performance no MASP, além de conceder premiações individuais a Sérgio Dias e Manito. (GOUVÊA, 1974a.).

Para além do impacto do trio progressivo, outros aspectos colaboraram para construir o clima otimista. Nesse momento, o fenômeno Secos \& Molhados, a despeito de sua efemeridade, oferecia possibilidade e a viabilidade ao rock como produto comercial no país - mesmo que de maneira ilusória (BAHIANA, 2005). Foi justamente no vácuo gerado pela cisão do grupo que muitos estreantes se colocaram e foram postulados como possíveis ocupantes daquela posição privilegiada no mercado fonográfico. Entre esses pretendentes, o jornalista Tárik de Souza elenca os "novatos" do Som Nosso (1974c, p. 108) - acompanhando, em grande medida, a lógica do cenário internacional, no qual, como já colocado, o rock progressivo ocupava lugar central na indústria musical.

O ano de 1974 assistiu também ao desenvolvimento incipiente do segmento musical voltado para o rock na grande imprensa (é nesse momento que a Folha de $S$. Paulo abre um espaço semanal e, posteriormente, diário direcionado ao gênero). Com isso, intensifica-se o papel da mesma enquanto mediadora cultural, entre o público e os artistas. Por fim, a intensa temporada de shows internacionais no país, compreendendo variados gêneros (para citar alguns: Alice Cooper, Tom Jones e Jackson Five no Anhembi, Billy Paul e The Supremes no Tuca, Astor Piazzolla no Teatro Municipal), e uma série de dados materiais - como cerca de vinte álbuns de grupos nacionais gravados, trinta novos grupos formados, trezentos concertos realizados e mais de um milhão de cópias de discos brasileiros vendidos (GOUVÊA, 1974i, p. 11) são aspectos que contribuem para a apreciação eufórica do ano. 


\section{artigos}

\section{Matheus Lacorte Naman Angelo de Castro}

\section{Caminhos e perspectivas ${ }^{23}$}

Um primeiro ponto a se destacar é a identificação de uma rede de sociabilidade em torno do rock progressivo, que circula por determinados espaços da cidade; com práticas que se inserem na tradição do rock progressivo, mas também a ultrapassam; e atuação significativa no cenário expansivo do rock nacional. Pode-se pensar que tal estilo ganha força no clima de euforia comercial do rock brasileiro - que tem como paradigma o "evento" Secos \& Molhados - em consonância com o que os "progressistas" internacionais proporcionavam à indústria cultural nos EUA e na Grã Bretanha.

Além disso, enquanto tradição musical e pensando nos elementos que essa, em alguma medida, circunscreve, o rock progressivo ataca a dois pontos criticados pela imprensa na caracterização do rock brasileiro enquanto movimento débil: de um lado a seriedade e o profissionalismo (os "pés no chão", como diz Gouvêa), e de outro o debate nacionalista (GOUVÊA, 1974e; SOUZA, 1974b; BAHIANA, 2005). Macan nos mostra como o estilo, no seu processo de constituição, constrói-se exacerbando uma face da moeda psicodélica, ou seja, seu lado apolíneo - em oposição a outros tributários do mesmo "caldo contracultural primordial", como o heavy metal, com sua natureza dionisíaca (1997). O rock progressivo se apresenta para o mencionado discurso de parte da imprensa, portanto, como um espaço simbólico no qual o rock nacional poderia se desenvolver com seriedade, equacionando e diluindo o aspecto negativo de um impulso demasiadamente "desbundado"24 que outros ramos desse

\footnotetext{
${ }^{23} \mathrm{~A}$ análise aqui desenvolvida não possui a intenção de apresentar resultados definitivos ou soluções conclusivas para as questões propostas. Isso pois a própria escassez de fontes e a falta de atenção e exploração do tema por parte da esfera acadêmica não o permitem. É possível, entretanto, indicar algumas perspectivas e caminhos a serem trilhados no futuro, com maior abrangência e cuidado.

${ }^{24} \mathrm{O}$ termo foi uma das formas nacionais de se chamar o movimento hippie. Remete à ideia de loucura, desvario, irracionalidade. Além disso, segundo Saggiorato, “Surgidos na década de 1970 e produzida pelo
} 


\section{artigos}

1974 e o rock progressivo paulistano

tipo de música ofereciam.

Quanto ao debate nacionalista, os termos são conhecidos: excessivo estrangeirismo e cópia de modelos exógenos são vistos como atitudes problemáticas. Se há um paradigma, no entanto, que pode ser útil dentro dessa querela, esse é, justamente, o progressivo. Com sua natureza eclética por excelência dentro da órbita do rock no início da década, “(...) o rock progressivo era, não só musicalmente, mas também socialmente um espaço de confluência da música popular e de sua cultura na primeira metade dos anos 1970" (MACAN, 1997, p.143, tradução própria ${ }^{25}$ ). Mais do que isso, a "progressão" pode ser encarada como uma atitude, uma pulsão no sentido da expansão e superação de estruturas musicais do rock, do R\&B e da música popular como um todo (ANDERTON, 2010).

É esse "espírito progressivo" que se verifica na fala de Sérgio Magrão, ao tratar da sonoridade do Terço ao longo de sua trajetória:

Era César de Mercês, Vinícius Cantuária na bateria e o Sérgio Hinds na guitarra. Aí já era um som, era progressivo, mas era um progressivo diferente. Porque a tecladaria (sic) não rolava, aquela tecladaria (sic) pesada. Veio a ter essa tecladaria (sic) quando Flávio entrou, foi diferente. (RESENDE e ASSIS, 2016, p.124)

Delineiam-se, dessa forma, dois níveis de progressividade: um estrato atitudinal, que Magrão postula como anterior à formação com Venturini, e outra mais diretamente identificável e associada a uma tradição específica (e alienígena), ou seja, àquela sinfônica - com notória utilização dos teclados e sintetizadores.

Nessa associação à etiqueta "progressivo", há, também, desconforto. Em uma entrevista, Pedro Baldanza diz:

discernimento das esquerdas, e também pela imprensa alternativa do período, os 'desbundados' ficavam à margem das questões sociais e políticas. Enquanto os "porras-loucas" praticavam ações políticas, onde volta e meia mudavam de partido, os desbundados acabavam rompendo com todos os vínculos políticos." (SAGGIORATO, 2008, p.28).

${ }^{25}$ No original: "(...) progressive rock was not only musically, but also sociologically, at the nexus of popular music culture between the early and mid-1970s." 


\section{artigos}

\section{Matheus Lacorte Naman Angelo de Castro}

Nunca gostei muito de rotular o Som Nosso de Cada Dia de Rock Progressivo porque acho que diminui muito o espectro do que é alcançado com o tipo de música que fazemos e que sempre quis fazer. Eu sempre chamei de "Musica Progressiva Brasileira" porque ela vai buscar todos os elementos de progressão em todos os ritmos brasileiros, mesmo de fora do rock inclusive. O que a torna mais abrangente, por isso sempre defendi que ela fosse "Musica Progressiva Brasileira", não só a música do Som Nosso como até mesmo de várias outras bandas. Sendo assim eu defino o som da banda, do Som Nosso de Cada Dia como "Musica Progressiva Brasileira". (MENESES, 2019)

Com isso, Baldanza evidencia como, muitas vezes, os estratos existentes - entre a pretensão e visão dos artistas, a recepção do público e os rótulos da imprensa e do mercado fonográfico - por vezes se sobrepõe e colidem.

Com sua contradição inerente, seu fundamento apolíneo e sua "atitude de progressão" (ANDERTON, 2010), o rock progressivo parece se encaixar singularmente no mosaico de interpretação histórica da cidade e do país. Diante desses aspectos, o estilo se revela como espaço de reflexão e reconfiguração, no campo do rock da década de 1970, de questões mais amplas, como a discussão sobre as tensões que compõe a realidade e a modernidade brasileiras. Se esse é o chão no qual se assenta grande parte do debate acerca da cultura nacional desde o modernismo na década de 20 especialmente tratando-se de São Paulo, e que permeia o próprio desenvolvimento histórico da cultura paulistana ${ }^{26}$ - o estilo oferece um potencial analítico e de interpretação particularmente rico.

\footnotetext{
${ }^{26}$ Aqui se afigura um potencial debate, em um espectro de longa duração. Observando o crescimento da cidade de São Paulo no final do século XIX, percebe-se um caráter de desenvolvimento sui generis, contraditório e quase espontâneo. A cidade permanece como palco de tensões disso decorrentes ao longo do século $X X$, além de estar inserida no contexto brasileiro que protagoniza uma das mais radicais e sofisticadas experiências de desenvolvimento econômico na história do capitalismo mundial. Tratando da cultura urbana paulistana, que emerge em meio a esse movimento, o historiador José Geraldo Vinci de Moraes (1997, p.186) diz: "Todo esse difuso processo permeado por um inquieto ritmo de tensões sociais, elaborado no espaço urbano, permitiu a construção e ao mesmo tempo marcou profundamente a memória coletiva das camadas populares paulistanas. Parece-nos que durante as décadas seguintes esta trama histórica possibilitaria o surgimento de vários momentos socioculturais repletos pela diversificação e contradição de elementos, constituídos a partir de inúmeros tipos de fusões e misturas.".
} 


\section{artigos}

1974 e o rock progressivo paulistano

\section{Bibliografia}

ANDERTON, Chris. A many-headed beast: progressive rock as European meta-genre. Popular Music, Cambridge, Volume 29/3, pp. 417-435, 2010. Disponível em: <https://www.jstor.org/stable/40926943?seq=1>. Acesso em: 06 mai. 2020.

BAHIANA, Ana Maria. Importação e assimilação: rock, soul, discotheque. In: Anos 70: Ainda sob a tempestade. (org.) Adauto Noaves, Rio de Janeiro: Aeroplano/Editora Senac Rio, 2005. p. 56-60.

CALADO, Carlos. Quatro modelos de espetáculo na história do jazz. In: 0 jazz como espetáculo. São Paulo: Perspectiva, 1990. cap. 2, p. 150-171.

ENCARNAÇÃO, Paulo Gustavo da. Rock cá rock lá: a produção roqueira no Brasil e em Portugal na imprensa - 1970 - 1985. 1ª edição, São Paulo: Intermeios/Fapesp, 2018.

FIORI, Adriano Anlves; CONTANI, Miguel Luiz. Das Formas Báquicas e do Grotesco Bakhtiniano em Imagens do Heavy Metal e do Hard Rock. Domínios da Imagem, Londrina, ano IV, n. 8, p. 7-18, mai. 2011. Disponível em: <http://www.uel.br/revistas/uel/index.php/dominiosdaimagem/article/view/23348>. Acesso em: 06 mai. 2020.

FISCHERMAN. Diego. Efecto Beethoven: Complejidad y valor em la música de tradición popular. Buenos Aires: Paidós Diagonales, 2004.

FRIEDLANDER, Paul. Rock and roll: uma história social. Rio de Janeiro: Editora Record, 2002. 


\section{artigos}

Matheus Lacorte Naman Angelo de Castro

FRITH, Simon et RIBAC, François. À propos du rock progressif: étiquetages, histoires, mise en spectacle et transformations du rock. Volume !, Guichen, $15: 1$, p. 135-149, 2018. Disponível em: < https://journals.openedition.org/volume/5766 >. Acesso em 06 mai. 2020.

GATTO, Vinicius Delangelo Martins. Rock Progressivo e Punk Rock: Uma análise sociológica da mudança na vanguarda estética do campo do Rock. 2011. 134 f. Dissertação (mestrado) - Instituto de Ciências Sociais, Departamento de Sociologia, Universidade de Brasília, Brasília, 2011.

MACAN, Edward. Rocking the classics: English progressive rock and the counterculture. Oxford University Press, 1997.

MENESES, Michael. Entrevistão com Pedro Baldanza - Som Nosso De Cada Dia. Disponível em: < http://www.portalrockpress.com.br/pedr\%C3\%A3o-som-nosso-decada-dia>. Acesso em: 26 de nov. 2019.

MONTANARI, Valdir. Rock: Alienação ou rebeldia? São Paulo: Vm produções culturais. 1992.

MORAES, José Geraldo V. Sonoridades Paulistanas. Rio de Janeiro: Funarte, 1997.

PAIVA, José Eduardo Ribeiro de. XXVII Congresso da Associação Nacional de Pesquisa e Pós-Graduação em Música, 2017, Campinas. Som Nosso de Cada Dia, a pioneira experiência progressiva brasileira. Campinas: 2017. p. 1-8.

PEREIRA, Carlos Alberto Messeder. O que é contracultura. São Paulo: Nova Cultural/Brasiliense, 1986.

QUEIROZ, Flávio de Araújo. Secos \& Molhados: transgressão, contravenção. 2004. Dissertação (Mestrado em Sociologia) - Universidade Federal do Ceará, Fortaleza, 2004. 


\section{artigos}

1974 e o rock progressivo paulistano

RESENDE, Vitor Henrique; ASSIS, Ana Claudia de. As diversas sonoridades do grupo de rock brasileiro O Terço: discussões sobre as identidades musicais nos anos 1970. ORFEU, Ano 1, n. 1, p. 109-131, 2016. Disponível em: <http://www.revistas.udesc.br/index.php/orfeu/article/view/7361/5678>. Acesso em: 06 mai. 2020.

RIBAS, Rafael Malvar. Contracultura musical brasileira: movimentos e particularidades. 2016. 110 f. Dissertação (mestrado em Educação, Arte e História da Cultura) - Centro de Educação, Filosofia e Teologia, Universidade Presbiteriana Mackenzie, São Paulo, $2016 . \quad$ Disponível em: <http://tede.mackenzie.br/jspui/handle/tede/2953 >. Acesso em 06 mai. 2020.

SAGGIORATO, Alexandre. Anos de chumbo: rock e repressão durante o Al- 5. 2008. 157 f. Dissertação (mestrado em História) - Instituto de Filosofia e Ciências Humanas, Universidade de Passo Fundo, Passo Fundo, 2008. Disponível em: <http://tede.upf.br/jspui/handle/tede/136>. Acesso em: 06 mai. 2020.

SANTOS, Daniela Vieira dos. Não vá se perder por aí: a trajetória dos mutantes. 2008. 175 f. Dissertação (mestrado) - Universidade Estadual Paulista, Faculdade de Ciências e Letras de Araraquara, Araraquara, 2008. Disponível em: <http://hdl.handle.net/11449/98969>. Acesso em: 06 mai. 2020.

Fontes:

I) Discográficas

O TERÇO. Criaturas da noite. Rio de Janeiro: Underground/Copacabana, 1975. 1 disco (37 min), 33 1/3 rpm, estéreo.

O SOM NOSSO DE CADA DIA. Snegs. São Paulo: Continental, 1974. 1 disco (37 min), 33 1/3 rpm, estéreo.

OS MUTANTES. Tudo foi feito pelo sol. Rio de Janeiro: Som livre, 1974.1 disco (42 min), 33 1/3 rpm, estéreo. 
Matheus Lacorte Naman Angelo de Castro

\section{II) Periódicas}

GOUVÊA, Carlos Alberto. Contemplados com o troféu de 1974. Folha de São Paulo, São Paulo, 11 dez. 1974a. Folha llustrada, p.38.

. Rock no MASP e no 13 de maio. Folha de São Paulo, São Paulo, 11 out. 1974 b. Folha llustrada, p. 38.

- As boas vibrações do rock e as más vibrações do rock. Folha de

São Paulo, São Paulo, 02 set. 1974c. Folha Ilustrada, p. 24.

. A primeira semana de rock 'n roll no Brasil. Folha de São Paulo, São Paulo, 16 dez. 1974d. Folha llustrada, p. 24.

. O nosso rock ainda é inexpressivo. Folha de São Paulo, São Paulo, 22 jul. 1974e. Folha llustrada, p. 18.

. Os Mutantes transformados. Folha de São Paulo, São Paulo, 29 out. 1974 f. Folha llustrada, p. 34 . "Som Nosso..." no Bandeirantes. Folha de São Paulo, São Paulo, 11 dez. 1974g. Folha llustrada, p. 38.

. O Terço. Folha de São Paulo, São Paulo, 27 nov. 1974h. Folha llustrada, p. 36.

. Rock 1974: um ano de rock. Folha de São Paulo, São Paulo, 30 dez. 1974i. Folha llustrada, p. 11.

. Mutantes. Folha de São Paulo, São Paulo, p.36, 16 out. 1974j.

. Rock e chuva, prova de fogo no Ibirapuera. Folha de São Paulo, São Paulo, 30 set. 1974k. Folha Ilustrada, p. 24.

LANCELLOTTI, Sílvio; PENIDO, José Márcio; DUTRA, Maria Helena; SOUZA, Tárik de. Os 


\section{artigos}

1974 e o rock progressivo paulistano

dez mais. Veja, São Paulo, p.46, 01 jan. 1975.

PENIDO. José Márcio. O som solar. Veja, São Paulo, p. 82, 06 nov. 1974.

PEREIRA, Clever. Som Nosso de Cada Dia - Snegs - SLP. 10146. Jornal do Brasil, Rio de Janeiro, 04 set. 1974. Serviço Completo, p.B06.

SOM NOSSO DE CADA DIA. Folha de São Paulo, São Paulo, 05 ago. 1974. Folha llustrada, p. 22.

SOUZA, Tárik de. Em geral. Jornal do Brasil, Rio de Janeiro, 20 out. 1974a. Esta semana, p. B05.

Opinião. Jornal do Brasil, Rio de Janeiro, 28 dez. 1974b. Música popular, p.B2.

. Compacto. Veja, São Paulo, p. 108, 21 ago. 1974c.

ZANETTI, Martha. Mutantes: Minha iluminação espiritual, minha própria vida. Rock, a História e a Glória. Rio de Janeiro, n 9, p. 17-18, 1975. 